\title{
The effect of cocaine on the nasal cavity and its differential diagnoses looking at three individual cases
}

\author{
Edmiston $\mathrm{R}^{1 *}$, Anmolsingh R ${ }^{1}, \mathrm{Yu} \mathrm{A}^{1}$, Chelliah $\mathrm{G}^{2}$, Chitale $\mathrm{S}^{2}$ and Kumar $\mathrm{N}^{1}$ \\ ${ }^{1}$ Department of ENT, Wrightington Wigan and Leigh NHS foundation trust, UK \\ ${ }^{2}$ Department of Rheumatology, Wrightington Wigan and Leigh NHS foundation trust, UK
}

\begin{abstract}
Systemic vasculitic conditions can present with sino-nasal symptoms. Due to the immunosuppressive agents used to treat such conditions it is vital that an accurate diagnosis is obtained prior to treatment commencing. We present a series of patients with significant nasal destruction and a diagnostic dilemma between a true vasculitic condition and a pseudovasculitis as a result of cocaine use. We review the investigations that can help to determine a definitive diagnosis, multidisciplinary approach needed and discuss the treatment strategies employed in our patients.
\end{abstract}

\section{Introduction}

Various systemic conditions including autoimmune, granulomatous, neoplastic, infective diseases as well as substance abuse can present with sino-nasal manifestations [1]. Due to the complexity of overlapping features, an accurate and prompt diagnosis poses a significant challenge for clinicians.

One particular area of difficulty surrounds the diagnostic uncertainty between a patient with cocaine induced midline destructive lesions (CIMDL's) and true primary systemic necrotizing vasculitis (PSNV) induced midline destruction. Amongst the subtypes of PSNV, midline lesions occur in up to $90 \%$ cases of granulomatosis with polyangitis (GPA) [2]; up to $69 \%$ in Eosinophilic granulomatous polyangitis (eGPA) [3] and up to $30 \%$ microscopic polyarteritis (MPA) found in [4].

Antineutrophil cytoplasmic antibodies (ANCA) play an important but cumulative role in assisting the diagnosis; along with clinical presentation, imaging, urine analysis and histology. Vasculitides can often demonstrate different patterns of ANCA positivity. GPA is associated with a positive C-ANCA pattern/PR3 antigen with MPA and EGPA being associated with P-ANCA/MPO antigen. Using the combined ANCA and associated target a sensitivity of $85.5 \%$ and specificity of $98.6 \%$ [5] can be achieved. The time to seroconvert can lead to confusion since many patients with GPA may have false negative levels for some time, despite having a significant sensitivity and specificity.

The presentation of pseudovasculitis, as a result of cocaine abuse, can be ubiquitous in both clinical findings as well as very similar serologicial results (positive ANCA levels) and a bewilderingly similar histological pattern. It is essential that an accurate diagnosis is made to prevent unnecessary exposure to immunosuppressants and also enable key decisions on management.

\section{Methods}

We present a series of three cases with a confirmed diagnosis of CIMDL. Data was collected from patient notes and online records. All three patients underwent the same investigative and management approach:

Step 1: Exclude systemic vasculitis
a. Refer to rheumatology
b. Urinalysis
c. Bloods

i.FBC, ESR, ANCA, Connective tissue screen, ACE, HIV, syphilis Step 2: Determine extent of disease

d. CT Sinus / CT Head and neck / CT thorax

Step 3: Restore some healthy nasal mucosa

e. Saline + lubrication

Step 4: Consider associated problems

f. Hearing aid referral

g. Speech and swallowing: Maxillofacial surgeon assessment

${ }^{*}$ Correspondence to: Edmiston R, Department of ENT, Wrightington Wigan and Leigh NHS foundation trust, UK, Tel: +86-20-81332566; E-mail: Rachel. edmiston@nhs.net

Key words: pseudovasculitis, sino-nasal symptoms, vasculitic

Received: September 05, 2018; Accepted: September 21, 2018; Published: September 25, 2018 


\section{Ethical considerations}

Patient confidentiality was maintained throughout the review by anonymizing data.

\section{Results}

\section{Patient one}

A 50yr old female was referred to the ENT department with nasal regurgitation; significantly hyponasal speech and a bilateral deterioration in her hearing

Oropharyngeal inspection revealed a $3 \mathrm{~cm}$ fistula to the right of midline arising from lateral to the incisive foramen anteriorly. Anterior rhinoscopy revealed an absent cartilaginous septum and partially eroded bony septum. The floor of the nose was found to be eroded bilaterally with only a thin layer of mucosa and the lack of visible normal lateral wall architecture. Significant crusting was present, but the post nasal space mucosa was healthy.

On further questioning she admitted to a two-year history of heavy cocaine abuse; having last used cocaine 18 months previously. She also confirmed 'aggressive' picking of her nose including using cotton wool buds to remove crusts from deep within her nasal cavity.

\section{Patient two}

A 41 yr old male patient presented to the maxillofacial department with a 4-week history of oral pain and difficulty in speaking. Examination findings included a granulating septal perforation and fistula of the soft palate. On further questioning he also reported a new history of bilateral hearing loss and a 6-month history of sinusitis like symptoms with nasal obstruction and discharge; managed in the community with numerous courses of oral antibiotics. He had no significant past medical or surgical history but admitted to a four-year history of cocaine use intranasally.

Clinical examination revealed a large septal perforation with a single nasal cavity. Significant crusting was identified within the nasal cavity with ulceration involving destruction of the turbinates.

\section{Patient three}

A $24 \mathrm{yr}$ old male presented to the respiratory physicians with a 3-year history of increasing shortness of breath and a single episode of haemoptysis. Further questioning revealed a long-standing history of nasal congestion, epistaxis and frontal headaches as well as a history of cocaine abuse having stopped 2 years previously.

Clinical examination revealed a saddle shaped deformity of the nasal bridge with a large septal perforation but a relatively healthy mucosal lining.

\section{Investigation results}

Table 1 summarizes the key laboratory investigative findings for the three patients. Importantly, all patients were found to have a mildly raised ANCA with PR3 positive, but no evidence of systemic vasculitis was identified. Follow-up investigations (Table 2) revealed no evidence of systemic involvement with normal renal function and urinalysis. Table 3 demonstrates that significant destruction was seen in $2 / 3$ of the patients CT imaging.

\section{Discussion}

\section{Key findings}

A diagnostic dilemma arises when a patient with known substance abuse presents to clinic with significant nasal destruction and the clinician has to be able to exclude a systemic vasculitic condition the unfortunate sequalae being that a multisystem disease can go undiagnosed. Early diagnosis of such conditions is key as advanced disease limits the potential benefit of therapy [6].

Cocaine itself is well recognized for its vasoconstrictive properties resulting in localized necrosis of tissues. The vasculitic response seen in CIMDL's is hypothesized to be a response from the cocaine but increasing evidence has identified levamisole adulterated cocaine to be more toxic in this way and is the main trigger to the vasculitic process. Crew identified that $50 \%$ of UK cocaine is cut with levamisole [7] - a synthetic imidazothiazole with immunomodulatory properties. When used in sufficient quantities, it can result in the localized tissue destruction seen with CIMDL's and also systemic vasculitis and agranulocytosis [8].

Our three cases aid in identifying key differences in presentation, serology and imaging which can help to differentiate CIMDL's from true vasculitidies. Table 4 provides a comparison between the vasculitic processes that can help with this diagnostic uncertainty looking at histology, serology and systemic involvement.

A key aspect of this is the requirement for histology. In 2016, the European League Against Rheumatism produced consensus statements providing guidance on the management of AAV patients [11] including discussions over the role of performing biopsies. In this study, they explain that a positive biopsy is strongly supportive of a diagnosis and biopsies are recommended to assist in establishing a new diagnosis. The important element to consider is the location from which they are taken. In GPA patients with renal involvement, diagnostic yield from renal biopsy can be as high as $91.5 \%$ and biopsies of nasal mucosa may be positive for inflammatory changes in $68.4 \%$. A large study looking at diagnostic yield from ENT biopsies revealed that they are often positive for non-specific chronic inflammation and it is significantly less common to find granulomas and vasculitis when compared to lung and kidney biopsies [12].

Table 1. Blood test results

\begin{tabular}{|c|c|c|c|c|}
\hline Blood tests & Case one & Case two & Case three & Normal ranges \\
\hline FBC & $\mathrm{Hb} 124$ & $\mathrm{Hb} 95$ & $\mathrm{Hb} 164$ & $115-165$ \\
\hline ESR & 29 & 68 & 3 & $0-27$ \\
\hline ANCA (IU/ml) & $\begin{array}{c}\text { MPO }<0.2 \\
\text { PR3 3.8 }\end{array}$ & $\begin{array}{c}\text { MPO }<0.4 \\
\text { PR3 4.5 }\end{array}$ & $\begin{array}{c}\text { MPO } 0.9 \\
\text { PR3 } 11\end{array}$ & $\begin{array}{l}<0.9 \\
<0.9\end{array}$ \\
\hline $\begin{array}{l}\text { DsDNA, Centromere B, SS-A, } \\
\text { SS-B, Sm, SmRNP, SCL-70, Jo-1, } \\
\text { Ribosomal P, Chromatin }\end{array}$ & Negative & Negative & Negative & \\
\hline RF & Negative & Negative & & \\
\hline ACE & Negative & Negative & & \\
\hline TPHA & Negative & Negative & & \\
\hline HIV & Negative & Negative & & \\
\hline
\end{tabular}


Table 2. Follow up investigations

\begin{tabular}{|c|c|c|c|}
\hline Follow-up investigations & Case one & Case two & Case three \\
\hline URINAYSIS & Normal & Normal & Normal \\
\hline $\mathrm{U}+\mathrm{E}$ & Normal & Normal & Normal \\
\hline Biopsy & Not performed & Nonspecific changes consistent with vasculitis & $\begin{array}{l}\text { Bronchial washings performed: No granulomas or overt necrotic material } \\
\text { seen }\end{array}$ \\
\hline
\end{tabular}

Table 3. CT sinus reports

\begin{tabular}{|l|l|}
\hline $\begin{array}{l}\text { Case one } \\
\text { CT SINUS }\end{array}$ & $\begin{array}{l}\text { Absence of hard palate with evidence of fistula between oropharynx and nasal cavity. Absent right middle turbinate and nasal septum. Erosion of medial pterygoid } \\
\text { plate. } \\
\text { Maxillary and ethmoid sinus mucosal thickening. }\end{array}$ \\
\hline $\begin{array}{l}\text { Case two } \\
\text { CT SINUS }\end{array}$ & $\begin{array}{l}\text { Extensive destruction in the paranasal sinuses with destruction of the hard palate on the left and fluid in bilateral mastoid air cells / middle ear clefts with dilatation } \\
\text { of the left ICA in the cavernous sinus. }\end{array}$ \\
\hline $\begin{array}{l}\text { Case Three } \\
\text { CT Head and neck } \\
\text { CT Thorax }\end{array}$ & $\begin{array}{l}\text { No overt signs of systemic vasculitis seen } \\
\text { (No CT sinus performed) }\end{array}$ \\
\hline
\end{tabular}

Table 4. Diagnostic features of ANCA associated vasculitidies

\begin{tabular}{|c|c|c|c|c|}
\hline & $\begin{array}{l}\text { MPA } \\
\text { Microscopic polyangitis }\end{array}$ & $\begin{array}{l}\text { GPA } \\
\text { Granulomatosis with polyangitis }\end{array}$ & $\begin{array}{l}\text { eGPA } \\
\text { Eosinophilic granulomatosis with } \\
\text { polangitis }\end{array}$ & Cocaine induced vasculitis \\
\hline Vessel size & Predominantly small vessel & Predominately small vessel & $\begin{array}{l}\text { Predominatly small to medium } \\
\text { vessels }\end{array}$ & Small vessel \\
\hline Serology & P-ANCA/MPO antigen & C-ANCA pattern/PR3 antigen & P-ANCA/MPO antigen & $\begin{array}{l}\text { C-ANCA pattern/PR3 antigen }(50 \% \\
\text { cases) } \\
\text { P-ANCA/MPO antigen (almost } \\
100 \% \text { [ [9] }\end{array}$ \\
\hline Histology findings [10] & $\begin{array}{l}\text { Necrotizing arteritis, } \\
\text { glomerulonephritis and capillaritis } \\
\text { common. } \\
\text { Granulomatous inflammation } \\
\text { absent. }\end{array}$ & $\begin{array}{l}\text { Necrotizing granulomatous } \\
\text { inflammation of upper and lower } \\
\text { respiratory tract. } \\
\text { Necrotizing glomerulonephritis, } \\
\text { pulmonary hemorrhage and ocular } \\
\text { vasculitis }\end{array}$ & $\begin{array}{l}\text { Necrotizing granulomatous } \\
\text { inflammation - eosinophil rich }\end{array}$ & Leukocytoclastic vasculitis \\
\hline Systemic involvement & Common & Common & Asthma & Rare \\
\hline
\end{tabular}

The implication of such a low diagnostic yield has led to our conclusion that nasal biopsies should not be part of routine practice (as demonstrated within our cases series). The exception to this is in the presence of very abnormal looking mucosa where other differential diagnoses are being considered such as lymphoma.

\section{Treatment strategies}

All three patients were managed by the same rheumatology, maxillofacial and ENT teams with short term oral steroids and abstinence from cocaine use.

Though the literature search is limited, we have found that a moderate dose of steroids normally $60-80 \mathrm{mg}$ on a reducing regime over 3 to 6 months works well as an immunomodulator to halt the vasculitic process. Very few patients, as described above, need steroid sparing agents (such as Azathiaprine). However, if a systemic vasculitic process has been identified, this would have been the next management step. Case one and two had significant palatal destruction requiring temporary management with an obturator and are both planed for reconstructive surgery with a radial forearm free flap when the mucosa is more healthy.

\section{Clinical applicability}

In summary we have identified that there are certain features that can aid in confirming a diagnosis of CIMDLs over other causes:

- CT scans often demonstrate soft tissue thickening of nasopharynx, soft palate and oropharynx with bony destruction of palate, lateral nasal wall, turbinates, septum and ethmoid sinuses [13].

- Biopsy should only be done to exclude malignancy where abnormal mucosa is seen.
- Serological markers can improve diagnostic yield with up to $56 \%$ c-ANCA positive with CIMDL [14] and more often very high titres of MPO ANCA antibodies [15].

- Once the diagnosis is confirmed, such patients must be managed by a multidisciplinary team:

- ENT surgeons are required to consider the potential of a systemic vasculitic condition, manage the nasal mucosa and aid in performing biopsies when needed.

- Rheumatologists can help with the diagnostic dilemma and also given advice on the management of such localized vasculitis as well as manage any associated systemic involvement.

- Maxillofacial teams can facilitate both temporary and long-term management of the extensive destruction that may occur.

\section{Key points}

1. CIMDLs to this extent are rare but it is important that we make an accurate diagnosis since the differential diagnosis is PSNV which needs an aggressive management plan.

2. Patients with confirmed vasculitis should be managed by specialist teams in a multidisciplinary approach with CIMDLs requiring input from ENT, Maxillofacial, rheumatology as well as allied teams such as audiology.

3. The diagnosis can be difficult, but clinicians should always enquire about cocaine use in the patient history. Diagnostic features that help to confirm a CIMDL rather than primary vasculitis include characterized destructive changes on $\mathrm{CT}$, but clinicians must be aware of the overlap in serology and histological features. 


\section{References}

1. Fuchs HA, Tanner SB (2009) Granulomatous disorders of the nose and paranasal sinuses. Curr Opin Otolaryngol Head Neck Surg 17: 23-27. [Crossref]

2. Falk RJ, Gross WL, Guillevin L, Hoffman GS, Jayne DR, et al. (2011) Granulomatosis with polyangiitis (Wegener's): An alternative name for Wegener's granulomatosis. Arthritis Rheum 63: 863-864. [Crossref]

3. Pagnoux C, Wolter NE (2012) Vasculitis of the upper airways. Swiss Med Wkly 142: w13541. [Crossref]

4. Olsen KD, Neel HB III, Deremee RA, Weiland LH (1980) Nasal manifestations of allergic granulomatosis and angiitis (Churg-Strauss syndrome). Otolaryngol Head Neck Surg 88: 85-89. [Crossref]

5. Choi HK, Liu S, Merkel PA, Colditz GA, Niles JL (2001) Diagnostic performance of antineutrophil cytoplasmic antibody tests for idiopathic vasculitides: metaanalysis with a focus on antimyeloperoxidase antibodies. J Rheumatol 28: 1584-1590. [Crossref]

6. Lapraik C, Watts R, Bacon P, Carruthers D, Chakravarty K, et al. (2007) BSR and BHPR guidelines for the management of adults with ANCA associated vasculitis. Rheumatology (Oxford) 46: 1615-1616. [Crossref]

7. http://www.erowid.ord/cocaine/cocaine_article2.shtml
8. Graf J, Lynch K, Yeh C, Tarter L, Richman N, et al. (2011) Purpura, cutaneous necrosis and antineutrophil cytoplasmic antibodies associated with levamisole adulterated cocaine. Arthritis rheum 63: 3998-4001. [Crossref]

9. Yates M, Watts R, Bajema I, Cid M, Crentani B, et al. (2016) EULAR/ERA-EDTA recommendations for the management of ANCA-associated vasculitis. Ann Rheum Dis 75: 1583-1594. [Crossref]

10. Devaney KO, Travis WD, Hoffman G, Leavitt R, Lebovics R, et al. (1990) Interpretation of head and neck biopsies in Wegener's granulomatosis. A pathologic study of 126 biopsies in 70 patients. Am J Surg Pathol 14: 555-564. [Crossref]

11. Diamantopoulos II, Jones NS (2001) The investigation of nasal septal perforations and ulcers. J Laryngol Otol 115: 541-544. [Crossref]

12. Trimarchi M, Nicolai P, Lombardi D, Facchetti F, Morassi ML, et al. (2003) Sinonasal osteocartilaginous necrosis in cocaine abusers: Experience in 25 patients. Am J Rhinol 17: 33-43. [Crossref]

13. Choi HK, Merkel PA, Walker AM, Niles JL (2000) Drug-associated antineutrophil cytoplasmic antibody-positive vasculitis: prevalence among patients with high titers of antimyeloperoxidase antibodies. Arthritis Rheum 43: 405-413. [Crossref]

14. Abdul-Karim R, Ryan C, Rangel C, Emmett M (2013) Levamisole-induced vasculitis Proc (Bayl Univ Med Cent) 26: 163-165. [Crossref]

15. McKinney E, Willcocks L, Smith C (2014) The immunopathology of ANCA- associated vasculitis. Semin Immunopathol 36: 461-478. [Crossref]

Copyright: $₫ 2018$ Edmiston R. This is an open-access article distributed under the terms of the Creative Commons Attribution License, which permits unrestricted use, distribution, and reproduction in any medium, provided the original author and source are credited. 